\title{
A Case of Obsessive Compulsive Disorder and Nicotine Abuse with Distorted Family Dynamics
}

\author{
Mr. Kannappa Setty $V^{1}$, Dr. Sanjeevkumar Manikappa ${ }^{2}$, \\ Dr. R Dhanasekara Pandian ${ }^{3}$
}

\section{ABSTRACT:}

In the 21 st century where communicable diseases are being replaced by behavioral problems, there is increased need for psychiatric social work interventions in dealing with psychosocial issues and restoring individual functioning. Changing familial and social structures too have negatives impact on the management of psychiatric disorders, especially in rehabilitation of persons with severe mental illnesses. Here is a case study that highlights both the importance of and challenges in psychosocial Interventions.

The case study illustrates the rehabilitation process of a client with obsessive compulsive disorders, poor secondary social support, distorted family dynamics and frequent relapses. The client was enabled to make informed choices about his illness, occupation and social rehabilitation.

Keywords: OCD, Family dynamics, Psychiatric social work interventions.

\section{BRIEF CLINICAL HISTORY:}

The client was apparently well tilled 15 year of his age when he was studying in high school. At this time, he started to get repetitive and involuntary sexual images. If he thought or saw any person, he would get these sexual images of them. Initially there was not much distress to the client \& could manage his daily activities including going to school regularly. Hence he didn't reveal this information to anyone in the family but later he found it very distressful, as he would get the sexual images of parents also and was unsuccessfully resisting the images by distracting his mind from the sexual images and at times doing some other activities. He would get these repetitive images 5 to 8 times a day lasting for 20 to 30 minutes each time. He was always preoccupied that the images might come repetitively. Eight months after the onset of the illness when his distress level increased, he revealed this to the parents.

\footnotetext{
${ }^{1}$ MSW,Mphil, PhD Scholar and Psychiatric social worker), PSW Department, National Institute of Mental Health and Neuro Sciences (NIMHANS), Bangalore, India

${ }^{2}$ MSW, Mphil, Ph.D. Freelance Consultant and Psychosocial Care Trainer, Bangalore

${ }^{3}$ MSW, Mphil, Ph.D, Additional professor, PSW Department, NIMHANS, Bangalore
} 
Family members took him to private psychiatrist and was diagnosed as OCD (ICD-10,2007) and put on medications. The client continued medications for two months \& later he stopped as his symptoms significantly improved. However, the client did not achieve pre-morbid levels and occasionally he would get these images causing mild distress. During this time he was seen to have low mood. As time passed on, excessive sexual images and suicidal ideas were reported by the client. Besides he was found to have homosexual behavior.

Then client was brought by family members to National Institute of Mental Health and Neuro Sciences (NIMHANS), Bangalore, and diagnosed with OCD predominantly obsessions. Since then client has been treated so many times both as inpatient and outpatient at NIMHANS. But most of the times he would come with drug defaults, irregular follow-up and social problems like conflict between parents, lack of finance support and lack of other support. After mother got separated from her husband, the client used to stay with his father. But his father was more critical, abusive and assaultive towards him. Since then his obsessions and suicidal ideas increased and along with that his homosexual behaviors also increased. He was actively abusing nicotine in the form of smoking (per day 15 cigarettes per day). Because of this he was sent out of home by his father. With this history the client came to NIMHANS and explained his illness and psycho social problems.

\section{FAMILY HISTORY:}

The client hails from rural background of low socio economic class nuclear family consisting of 2 members. He is the $1^{\text {st }}$ child born of non- consanguineous marriage. His mother got divorced from her husband, got second marriage and she is staying with daughter and second husband at her parents' village, but the client was staying with his father and since 3 months due to adjustment problems father has thrown the client out of home and he is now homeless. There is significant family history suggestive of mental retardation in the client's sister who is now staying with her mother. 


\section{Family Genogram}

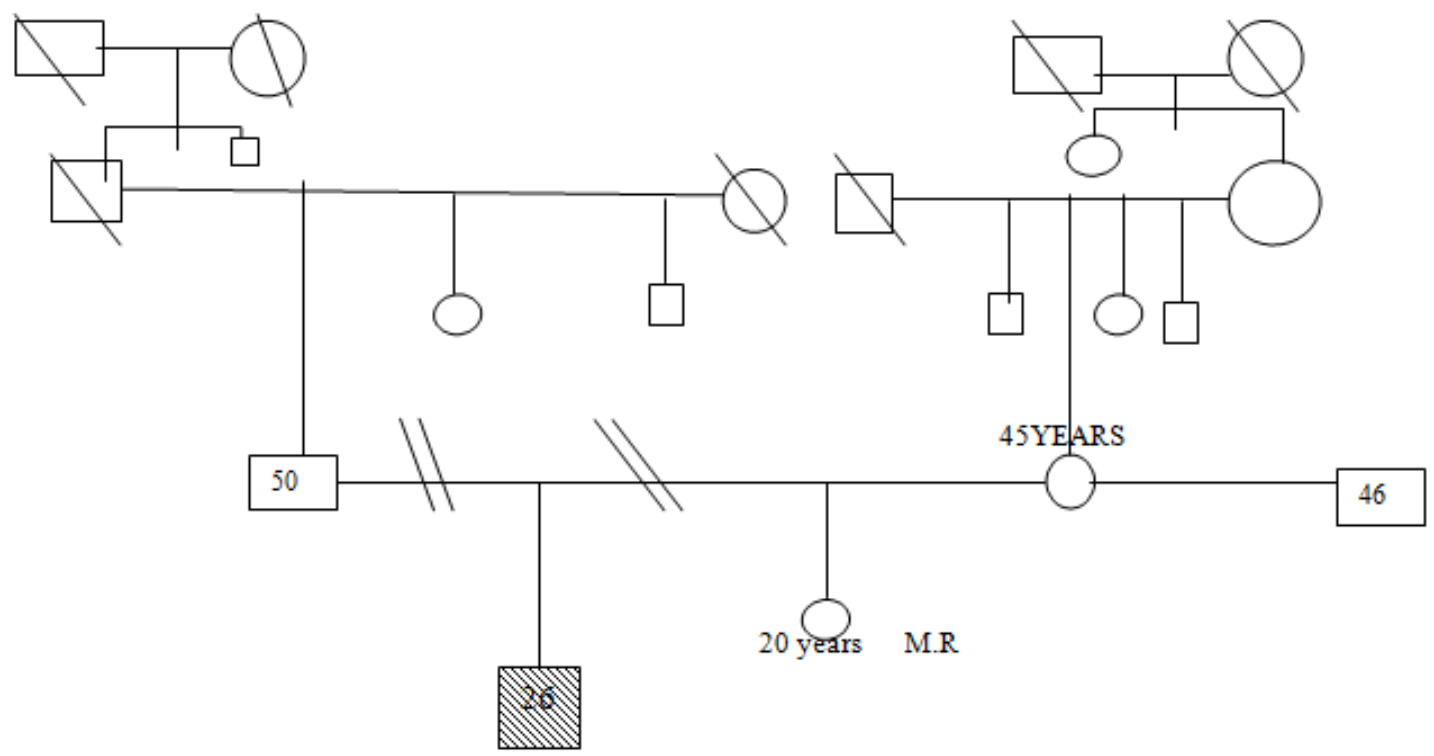

\section{FAMILY COMPOSITION:}

Father -He is 50 year old, educated up to SSLC and was working in Karnataka state road Transport Corporation. He has taken voluntary retirement. Father is not very concern about the client, the client is not attached to father and they both do not share healthy relationship. He always gets into argument and fight with the client. He is described to be very non cooperative and criticizing father.

Mother- She is 45 year old, educated up to SSLC and homemaker. She was attached with the client, but she got divorced due to adjustmental problems and abusive and assault behaviors of her husband. She is currently staying separately with her second husband and daughter.

Sibling: she is 20 years old and educated up to $7^{\text {th }}$ std. She is reported to mentally retarded and staying away from the client's family with her mother.

\section{FAMILY INTERACTION PATTERN:}

Interaction patterns between parents: Parents were not supportive towards each other. They got divorced 15 years back and they live separately without having any relationship. It was reported that children were free to approach their parents but due to divorce of parents they cannot meet them. 
Interaction between the client and his parents: When the client was child, his parents got separated due to adjustment problems and alcohol abuse in father. Then onwards the client is staying with father and the client's sister is staying with mother. The client speaks to his mother occasionally over phone which is not liked by his father. His father does not interact with him properly. He always criticizes him for trivial issues and does not try to meet his needs.

Interaction among siblings: Until client's mother got separated, there was good interaction between client and his sister. They would play together, would share things and support each other. Now there is not communication between them.

\section{FAMILY DYNAMICS:}

Boundaries and Subsystems: Boundaries in the system are closed and rigid where father does not allow anyone in the system and outside the system to express their views and suggestions. For example, he would criticize his wife a lot and beat her up for small reasons, which eventually led her to get divorced from him. Even now he is very critical of his son's behavior and he wishes that his things should run in the family.

Family Developmental Stage: Family with launching young adult (Duvall, 1977)

Leadership and decision-making: Client's father is the nominal and functional head of the family. Autocratic nature of decision making process is present in the family. Other family members are not consulted for their views while making decisions. Father as a leader of the family is not accepted by its members, which has adverse impact on implementation of decisions taken by him alone.

Role structure and Functioning: Roles are not well defined in the family. While allocating roles, members are not consulted. They are just asked to do certain tasks by the leader. Hence, there is lack of role execution by family members. Father as the leader of family has failed to do his job adequately.

Communication: The members of the family used the faulty communication for their needs and wants. Therefore, communication pattern in the family appears to be indirect and not clear. There is huge point of argument in the family.

Reinforcement: Negative Reinforcement is present from father for both adaptive and maladaptive behavior of the family members.

Cohesiveness: Family is not cohesive. Family rituals are absent. They usually do not go anywhere. They do not have even food together.

Adaptive patterns: Family members are unable to cope with the stressful events effectively. They are not strong enough to cope with the problems generally in times of difficulties. All the other family members are not supportive and no one is there to advise the client to be positive in difficult situations. They do not come together in times of difficulties and talk about their 
problems. But sometimes mother speaks over the phone and gives support and encouragement to him. Because of step father's presence with his mother, the client doesn't want to go there.

Social support: Primary support is not adequate as the members of the family especially father and mothers are not available to support the client. Secondary support from relatives and friends is also inadequate. Tertiary support is available adequately from NGO, psychiatric rehabilitation centre and NIMHANS.

\section{PERSONAL HISTORY:}

Birth and early development: The client was born out of fulltime normal delivery at home, cried at birth and there were no complications. Developmental milestones are reported to be normal.

Behavior during childhood: Behavior of the client during childhood was reported to be normal, there is no history of thumb sucking or nail biting or bedwetting or any other behavioral problems.

Physical illness during childhood: No physical illness was reported during childhood.

Schooling: Client started schooling at the age of five, was a good student and educated up to 1 year B.A

Sexual history: Client attained knowledge about sex from magazines and peers. He was involved in homosexual activity which involved both oral and anal sex. The client is more attracted towards males.

\section{TEMPERMENTAL HISTORY:}

Attention and concentration: The client was reported to be attentive while doing any work or studies and had the ability of concentrating on the activity.

Activity level: Activity level was normal. He would perform his activity as everybody does.

Regularity of habits: Client was flexible in his daily routine. Though he was maintaining a regular routine, he would be flexible in his day-to-day activities.

Initial Reaction: Client was shy to approach new people and was hesitant to new situations and persons. But later he would become familiar.

Adaptability: Client described that he was not able to adjust easily to the new environment.

Intensity: Client described that he was jumping up and excited for any positive events or good thing in his life and could not easily adjust to the disappointments as well.

Mood: Parents described his mood to be cheerful at most of the times. 
Distractibility: File described the client to be able to stay focus on \& complete the tasks.

\section{SOCIAL ANALYSIS AND DIAGNOSIS:}

Mr. S, 26 year old, unmarried Hindu male, educated up to B.A, from nuclear family with low socioeconomic status of rural Karnataka came to NIMHANS with history of continuous illness of repetitive thoughts and sexual images, suicidal ideas, homosexual behaviors, feeling anxious, preoccupation with these thoughts and images, socio-occupational impairment, unable to adjust with different environments and lack of interest in daily activities and nicotine abuse in the form of smoking cigarettes. With these symptoms he was diagnosed as Obsessive compulsive disorder predominantly obsessions and with NDS.

The client's family is found to be autocratic and judgmental in nature. Right from the beginning of marital life, client's parents would not get well along with each other. They would fight over trivial issues which sometimes used to lead to physical abuse and non communication for some time. Client's father's criticality, dominating nature and none caring towards his wife and other family members were the main reasons for these fights between them. When client's mother could not tolerate his behavior, she divorced him and got second marriages around 15 years ago from now.

They have two children- client and his younger sister. After divorce the client stayed with his father and his sister was taken by his mother. Family dynamics reveals rigid boundaries, autocratic leadership by father, and non acceptance of the leader, faulty parenting, faulty reinforcement, inadequate primary support and negative ways of coping with the situations.

Family has very poor understanding of client's illness. Instead of taking him to hospital, his father would criticize him, saying "You are pretending to be ill and you do not have any problem". This would bother the client more than illness itself. His father would not give him money for medicines and would not allow him to do any work at home.

The client's poor understanding about the illness has also contributed to some of the relapses. He would stop medicines whenever symptoms came down, thinking that he has recovered and there is no need to take medicines any more. Owing to frequent relapses and non compliance to medication, client's father sent him out of home. 
Pictorial Presentation of the Psychosocial Diagnosis

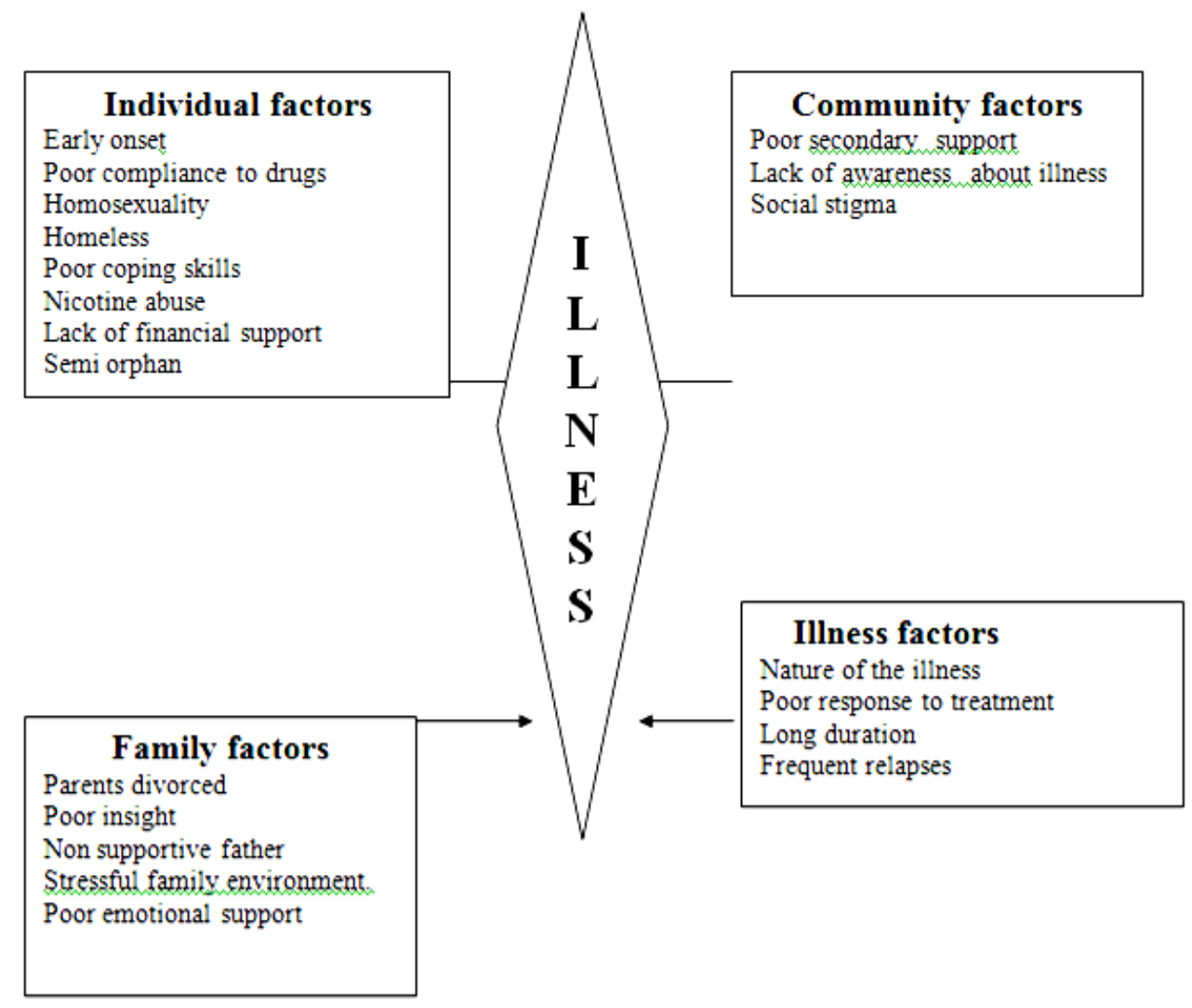

\section{PSYCHOSOCIAL MANAGEMENT:}

\section{Goals of interventions at individual level:}

- To enhance client's insight about the problem and treatment

- To enable him maintain abstinence from tobacco use

- To enhance his coping ability

- To provide supportive environment

- To reunite him with his family.

$\underline{\text { Interventions carried out at individual level }}$

* Building up rapport with the client.

* Supportive work.

* Motivational interviewing.

* Psycho education

* Teaching coping strategies.

* Activity schedule

* Group therapy

* Rehabilitation 


\section{Goals of interventions at family level:}

- To remove ignorance of family members about the illness.

- To enable them understand pathological family functioning

- To address expressed emotions

- To enrich their interaction style in a better way.

\section{Interventions at family level:}

As there were many family issues which have been playing as precipitating and maintaining factors for client's illness, the therapist used different modes for contacting his family members, but nobody including his father came to meet him. This is reason why family level issues could not be dealt with till client was in the hospital.

\section{No of Sessions had:}

$$
\checkmark \text { Individual } \quad 15 \text { sessions }
$$

\section{$\underline{\text { Interventions individual level: }}$}

\section{A. Rapport building:}

As a first step of the intervention process, therapeutic relationship between the client and therapist was established to achieve the objectives set for helping the client solve his problems and overcome difficulties. This relationship was maintained throughout the interventions process in a meaningful way.

\section{B. Supportive work with the client:}

Supportive expressive work was widely used in which the client was encouraged to discuss his thoughts \& levels of anxiousness and feelings and to help him cope with his thoughts. Supportive counseling helps ease the distress trigger by the obsessions, and addresses the low feelings.

Initially the psychiatric social worker introduced the client's illness. Afterward the focus of the intervention was explained to the client and in this process; rapport was established with the client. Support was provided to the client to enable him to ventilate his emotions. In the first session, the client was able to express his difficulties and emotions \& could realize the need for changes in his thinking and sense of independency. Client was allowed to ventilate about his experience with the obsessions. Client was helped to let go off the distress by explaining the nature of the illness. Techniques of supportive psychotherapy such as ventilation, reassurance, and guidance were employed accordingly to deal with the emotional issues of the client which helped in instilling the hope for recovery ( Nolvis, Rojcewicz, and Peele,1993). 


\section{Motivation enhancement therapy:}

Theoretical basis for intervention: The motivational interviewing technique is a key component of MET. It was shown to overcome client s' reluctance to enter treatment more effectively than did conventional techniques (Miller, Meyers \& Tonigan 1999) MET is very effective and it is found to help in decreasing each day for heavy drinkers and smokers decrease the consequences of smoking, increase of abstinence day, increase global assessment of function, and improve in stage of change readiness and treatment.

There are different stages of change in eagerness among smokers and drinkers. According to Millers model,(1999) the different stages are Pre-contemplation (Not currently considering change: Ignorance is bliss) Contemplation (Ambivalent about change), Preparation (Some experience with change and are trying to change) Action (Practicing new behavior) Maintenance (Continued commitment to sustaining new behavior) Relapse (Resumption of old behaviors).

Intervention-When client came to NIMHANS, he was in the contemplation stage as he considered both the existence of a problem and the feasibility and costs of changing the problem. In order to motivate the client to progress further and to determine himself to abstain from smoking, support was given to him by implementing the brief intervention through the technique of FRAMES (Feedback of personal risk or impairment, personal Responsibility for change, Advice to change, Menu of alternative change options, Empathy and facilitation of client Selfefficacy or optimism.

\section{Psycho- Education:}

Psycho-education is the specialized education that comprises of educational endeavors directed towards the clients and their families with an aim to help prevent relapse of mental illnesses and restoration of health for mentally ill. Psycho-education helps the mentally ill by improving treatment adherence (Ashutosh Atril and Manoj Sharma 2007).

At the initial session, the client understanding of the illness was elicited. The client thought that medication needs to be changed according to the thoughts $\&$ he was not aware of the importance of continuous medications in the treatment of illness. The client was explained about the illness. This includes the nature of the illness, symptoms, causes, treatment, management, prognosis and the need for regular medications and follows up. He was explained about the importance of the exposure $\&$ response prevention in the treatment of the OCD.

\section{E. Activity scheduling:}

During the stay at the ward, Psychiatric Social Worker planned activity schedule according to the interest of the client. As he had difficulty in interacting with other people when he was symptomatic, making friends was added in the activity schedule. Introducing oneself to the other ward mates and their parents, greeting them, interacting with strangers, attending library, going 
for walk, visiting temple and other daily living activities were included as part of his daily activities

The progress on the activity schedule was evaluated everyday and client received positive reinforcement in the form of appreciation when he performed the tasks. If he was not able to do any of the tasks, he was motivated and assisted to overcome his difficulty and asked to perform the next day. He was encouraged to follow it and mark whenever he completed the activity (Bellack et al., 1985).

\section{F. Teaching coping strategies:}

Rationale basis for intervention- Problem solving technique changes the areas of the person's life that are creating significant stress, and contributing to the depression and suicidal ideas. Problem solving therapy involves several key stages: (i) decide which problems to be tackled first, (ii) Agree goals, (iii) work out steps necessary to achieve goals, (iv) decide tasks necessary to tackle first step, (v) review progress at next therapy session, including difficulties that have been encountered and (vi) decide next step, depending on the progress and agree subsequent tasks, (vii) proceed as above to agreed goals, or redefine problems and goals, (viii) work on further problems (Keith Hawton and Joan Kirk 1989).

Intervention -In the analysis it was found that the ways of handling problems in life for the client was to resort to smoking and there were family adjustment problems. In order to overcome the maladaptive ways of handling problems, the client was exposed to the problem solving technique to enable him to handle his day to day problems as well as to enhance his coping mechanisms. Client was encouraged to learn the better ways of coping stressors. Both the client and therapists sorted out ways to enhance the client's coping and problem solving technique by following the above mentioned step. In between the sessions, ways of solving his family related issues were discussed:

\section{G. Group therapy:}

Rationale basis for intervention- Recent studies have shown that group therapy educates clients about treatment compliance, the number of relapses can be reduced by $15 \%$ by decreasing the stigma associated with mental disorder (Rothbaum \& Astin, 2000). Client's who have combined group treatment and medication can have a less severe course of disease than client's who receive medication alone in terms of poor family interactions, marital failures and the need for readmission to hospital (Rothbaum \& Astin, 2000).

Intervention- Client was exposed to group session with other inmates to have better understanding about the problem as well as to enhance the motivational level of the client (Heap, 1977). It was seen in the group session the client showed keen interest in analyzing and working with his problems. Client in the group was psycho-educated about the problem as well as to be aware of the techniques of maintaining abstinence, preventing relapse and drug adherence. This 
interaction with other clients helped him a lot in understanding his problems and what are the ways out.

\section{H. Rehabilitation:}

Rationale basis for intervention-Skill training, drug therapy, and community support strategies are the three primary intervention techniques used by practitioners attempting to rehabilitate severely psychiatrically disabled clients.

Intervention- The therapist made a couple of attempts to contact family members of the client, but nothing could work out so far. As his father has thrown him out of the family, he is now homeless. Hence, for better functioning of the client, rehabilitation was incorporated in the intervention to enhance the socio-occupational functioning of the client. In order to cope up with family problems and other adjustment problems, client needed short term shelter. So the therapist contacted rehabilitation centre in the Bangalore. After discharge the client was placed in Shre Shiradi Sai Baba old age home and rehabilitation centre in Bangalore. After placement, he is now maintaining very well. He is involved in activities like helping other clients, going to market and reading books.

\section{OUTCOME:}

As a result of psychiatric social work intervention, the client got insight into the illness and treatment methods. He has understood the importance of the long term medication \& regular follow up. He was able to carry out the day today activities with less OCD symptoms. His motivation level to quit smoking was enhanced. His coping abilities were also enhanced. A supportive environment was provided to the client and he could be placed in rehabilitation centre. He felt more confident of rejoining his family in future.

\section{FUTURE PLAN}

Psychiatric social worker set few future plans as client had inadequate family and social support. They are; ensuring regular follow up of the client to NIMHANS and drug adherence, working on continuous emotional and material support to the client and addressing his family issues if his family members come forward.

\section{LIMITATION:}

* The present case study did not have adequate information as the client's family members did not come to hospital or respond to the therapist's attempts.

* Family issues could not be dealt with because the client's father and relatives did not come for sessions in spite of repeated calls made and letters sent by the therapist. 
Psychiatric social work intervention would not be difficult as most of the clients will have family support in our society. Since client family dint available for entire treatments process this case study cannot be generalized to all other clients in the country.

\section{CONCLUSION}

The Psychiatric social work Intervention is effective and beneficial in dealing with clients with mental illness. It also prevents other family members from mental illness.

\section{REFERENCES}

Alan S. Bellack and Michel Hersen (1985), Dictionary of Behavior Therapy Techniques, Pergamon Press, New York.

Ashutosh Atril and Manoj Sharma, 2007, Psychoeducation: Implications for the Profession of Health Education. Californian Journal of Health Promotion, Volume 5, Issue 4, pp.32-39. Available from < http://www.csuchico.edu/cjhp/5/4/032-039-atri.pdf> 10 January 2009

Hand book of psychiatric social work, PSW department NIMHANS.

Keith Hawton, Paul M. Salkovskis, John Kirk and David M. Clark (1989), Cognitive behavior Therapy for Psychiatric Problems- A Practical Guide, Oxford University Press, New York

Ken Heap ,Group theory for social workers: An introduction, Pergamon press ,1977

Mathew Varghese, Anisha Shah, and GS Udaya Kumar, Family Intervention and Support in Schizophrenia: A manual on Family intervention for the Mental Health Professional, NIMHANS, Bangalore

Peter. N. nolvis, Stephen.J.rojcewicz, Roger peele, clinical manual of supportive psychotherapy, 1993, American psychiatric press, Washington.

Reading Material for the certificate course in Family Therapy (2001), Family psychiatry Centre, NIMHANS, Bangalore

Rothbaum BO \& Astin MC (2000). Integration of pharmacotherapy and psychotherapy for bipolar disorder, Journal of Clinical Psychiatry, vol. 66, pp. 68-75.

The ICD-10 Classification of Mental and Behavioral Disorders- Clinical Descriptions and Diagnostic guidelines (2007), A.I.T.B.S. Publishers, Delhi

William R. Miller and Stephen Rollnick (1999) Motivational Interviewing- Preparing People to Change Addictive Behavior, The Guilford Press, London 